\title{
Synthesis and Characterization of Soy Lecithin Coated Magnetic Iron Oxide Nanoparticles for Magnetic Resonance Imaging Applications
}

\author{
FARZANEH HOSSEINI and MIRABDULLAH SEYED SADJADI* \\ Department of Chemistry, Science and Research Branch, Islamic Azad University, Tehran, Iran. \\ ${ }^{*}$ Corresponding author E-mail: m.s.sadjad@gmail.com \\ http://dx.doi.org/10.13005/ojc/320608 \\ (Received: October 24, 2016; Accepted: December 13, 2016)

\begin{abstract}
In this work, we report synthesis and characterization of soy lecithin (SL) coated iron oxide nanoparticles by one step co precipitation method in an aqueous solution using ferrous and ferric salts (1:2), different values of $\operatorname{SLP}(0.0,1.5$ and $6 \mathrm{gr})$ and ammonia to adjust $\mathrm{pH}=10$. Characterization of the samples (labeled as SPION, "SPION ${ }_{1.5}$ and SPION $_{6}$ ) carried out using X-ray powder diffraction (XRD) patterns indicated formation of magnetite $\left(\mathrm{Fe}_{3} \mathrm{O}_{4}\right)$ nanoparticles with a calculated average crystalline size of $25 \mathrm{~nm}$ for naked $\mathrm{Fe}_{3} \mathrm{O}_{4}, 13 \mathrm{~nm}$ for "SPION ${ }_{1.5}$ " and $9 \mathrm{~nm}$ for "SPION 6 " nanoparticles by Sherrer's equation. FT-IR spectroscopy and Thermo-gravimetric analysis (TGA) were used to investigate the presence of "SL" on the nanoparticles surface. The images and morphology of the samples were examined on scanning electron microscope (SEM). Detailed chemical analysis of the nanoparticles was obtained from energy dispersive X-ray (EDX) data. To measure magnetic properties of the prepared samples, a Vibrating Sample Magnetometer (VSM) was used and a Dynamic Light Scattering (DLS) instrument was finally used to measure hydrodynamic diameter of the nanoparticles. The results revealed that the soybean lecithin was coated on $\mathrm{Fe}_{3} \mathrm{O}_{4}$ nanoparticles surface and smaller particle size was obtained with increased concentrations of soybean lecithin.
\end{abstract}

Keywords: Water dispersed solution; Soy Lecithin; Surface modification; Iron oxide magnetic nanoparticles (SPION).

\section{INTRODUCTION}

Magnetic Iron oxide nanoparticles (SPION) with appropriate surface chemistry have been attracted a lot of interest for their numerous applications ${ }^{1-3}$ such as magnetic resonance imaging contrast enhancement $\mathrm{t}^{4,5}$, immunoassay, detoxification of biological fluids, hyperthermia ${ }^{6}$, drug delivery systems $\mathrm{s}^{7,8}$ and in cell separation and immobilization of biomolecules such as nucleic acids or proteins ${ }^{9}$, etc. All of these biomedical applications require that these nanoparticles should have high magnetization values and size between 10 to $100 \mathrm{~nm}^{10}$ with an overall narrow particle size distribution, so that the particles could have uniform physical and chemical properties and 
have to be optimized for intravenous injection and most prolonged drug circulation time in the body. Furthermore, magnetic nanoparticles need to have special surface coating to be not only non-toxic and biocompatible but also to allow a targetable delivery with particle localization in a specific area ${ }^{11}$. To this end, to prevent formation of the large aggregates and preparation of an appropriate substrate for functional groups (amines or carboxylic acid) for bio conjugation with certain drugs we attempted to synthesize in one pot soy lecithin protein coated iron oxide nanoparticles using in situ coating coprecipitation procedure. The size, morphology, and magnetization of the prepared samples as well as, the effect of different values of SL coating on the size and magnetic properties of magnetic nanoparticles will be finally reported

\section{MATERIALS AND METHODS}

\section{Materials}

Ferric chloride hexahydrate $\left(\mathrm{FeCl}_{3} \cdot 6 \mathrm{H}_{2} \mathrm{O}\right)$ and Lecithin from Soybean were obtained from Sigma-Aldrich. Ferrous sulfate heptahydrate $\left(\mathrm{FeSO}_{4} \cdot 7 \mathrm{H}_{2} \mathrm{O}\right)$, and ammonium hydroxide $25 \mathrm{wt} \%$, were purchased from Fluka (Buchs, Switzerland).

\section{Methods}

X-ray diffraction patterns (PW 1800 PHILIPS), and FT-IR spectra (Perkin Elmer spectrum 100) were used to determine crystal structure of SPION and its lecithin coated products. The morphology, particle size and particle size distribution determination were carried out using Scanning electron microscopy (Philips EM208) and Dynamic Light Scattering (Otsuka, LPA-3000, 3100, Japan) analysis. The presence of lecithin on SPION was studied by Thermogravimetric analysis (TGA 931 TA Perkin-Elmer instruments) and Eltra-cs analyzer. The magnetic properties were finally evaluated using a Vibration Sample Magnetometer (VSM, Quantum Design PPMS-9).

\section{Preparation of SL Coated Iron Oxide Nanoparticles}

Soy lecithin coated iron oxide nanostructures were synthesized following a simple one-step coprecipitation approach. Initially, $2.7 \mathrm{~g}$ of ferric chloride hexahydrate $\left(\mathrm{FeCl}_{3} \cdot 6 \mathrm{H}_{2} \mathrm{O}\right)$ and $1.39 \mathrm{~g}$ of ferrous sulphate heptahydrate $\left(\mathrm{FeSO}_{4} \cdot 7 \mathrm{H}_{2} \mathrm{O}\right)$ (molar ratio $2: 1$, respectively) were dissolved in $50 \mathrm{~mL}$ deionized water and the mixture, stirring vigorously under $\mathrm{N}_{2}$ atmosphere was heated to $85^{\circ} \mathrm{C}$ and was drop wisely added $200 \mathrm{~mL}$ of ammonia solution (25\%) containing $0.00,1.50$ and, $6.00 \mathrm{~g}$ of soy lecithin deoxygenated by dry nitrogen stirring over a period of 20 min until observing change of color from dark orange to black. Stirring was steadily continued for more than $2 \mathrm{~h}$ followed under rapid stirring in $\mathrm{N}_{2}$ atmosphere. The precipitates were finally removed by magnetic decantation and washed for several times with water to make it free of any residual salts, until obtaining $\mathrm{pH}=7$. The final products were dried in a vacuum oven at room temperature for $24 \mathrm{~h}$.

\section{Preparation of water dispersed solution of SL Coated Iron Oxide Nanoparticles}

In order to obtain good hydration of lecithin coated iron oxide nanoparticles, considering that lecithin is a mixture of phospholipids with phosphatidylcholine (PC) as a main component (up to $98 \% \mathrm{w} / \mathrm{w})$, we prepared a dispersed aqueous solution of lecithin coated iron oxide nanoparticles by dispersing our synthesized lecithin coated iron oxide nanoparticles $\left(\mathrm{SPION}_{6}\right.$ ) in water or in an isotonic aqueous solution by means of extensive mixing at temperature $40-60^{\circ} \mathrm{C}$.

\section{RESULTS AND DISCUSSION}

\section{X-ray power diffraction study}

Fig. 1 represents XRD patterns of $\mathrm{SPION}_{6}$ (a); $\mathrm{SPION}_{1.5}$ (b) and naked $\mathrm{Fe}_{3} \mathrm{O}_{4}$ (c) nanoparticles. This results show clearly that, all the patterns are in good agreement with the standard diffraction spectrum (JCPDS Card No. 19-0629) ${ }^{12}$ and the synthesized products were crystalline $\mathrm{Fe}_{3} \mathrm{O}_{4}$. The average particle size was calculated to be at about 25 $\mathrm{nm}$ for naked $\mathrm{Fe}_{3} \mathrm{O}_{4}, 13 \mathrm{~nm}$ for $\mathrm{SION}_{1.5}$ and $9 \mathrm{~nm}$ for $\mathrm{SION}_{6}$ nanoparticles by using Sherrer's equation:

$$
\mathrm{D}=\mathrm{K} \lambda /(\beta \operatorname{Cos} \theta)
$$

Where, $\mathrm{D}$ is the particle size and $\mathrm{K}, \lambda, \beta$ and $\theta$ denote Sherrer constant, $\mathrm{X}$ - ray wavelength, the peak width of half-maximum and the Bragg angle. These results and comparing the crystalline size obtained indicate that, SLP has served as a surfactant and coating agent in the precipitation of $\mathrm{Fe}_{3} \mathrm{O}_{4}$ nanoparticles and we found that, the size of 


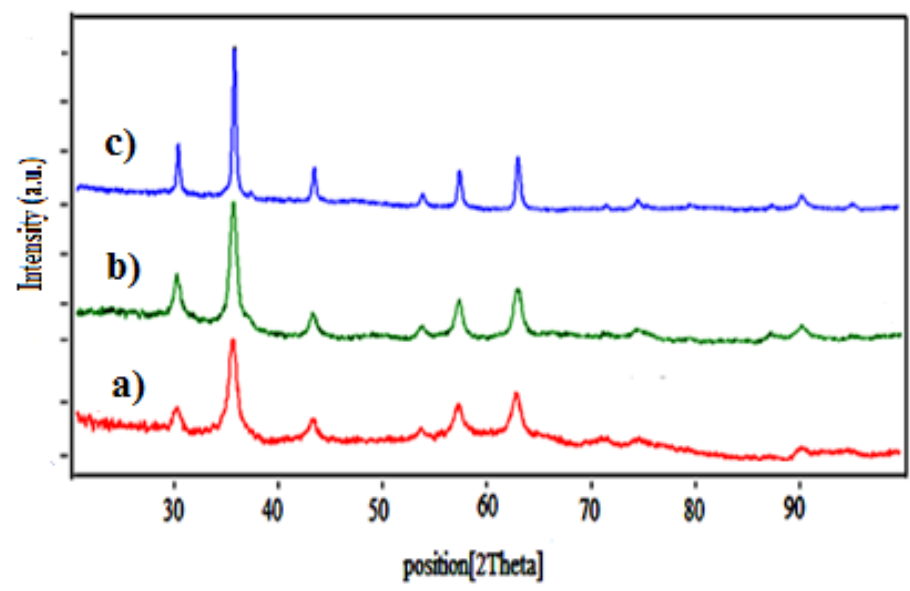

Fig. 1: X-ray power diffraction patterns of: a) SPION $_{6}$; b) SPION $_{1.5}$ and c) Naked- SPION

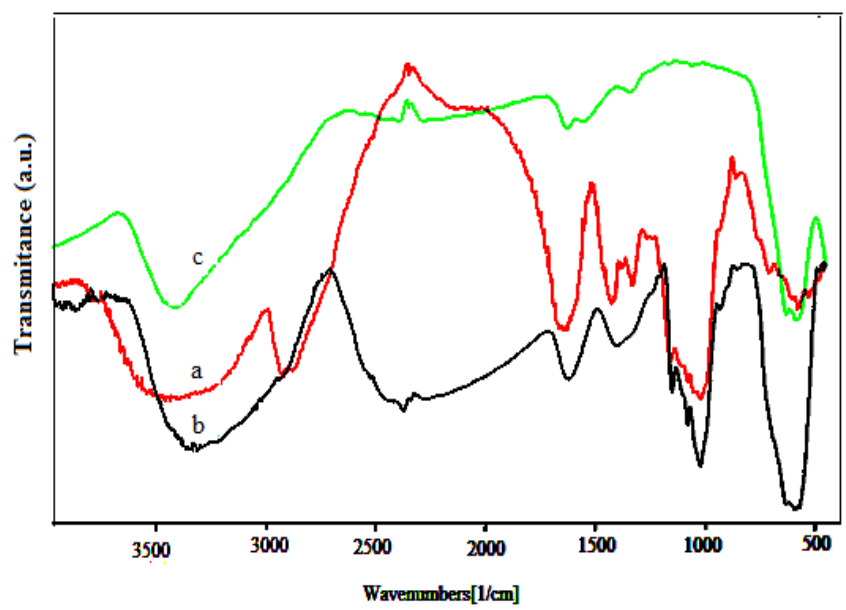

Fig. 2: FTIR spectra of: a) free Soy lecithin protein; b) $\mathrm{SPION}_{6}$; c) SPION

Table 1: FTIR band assignment for naked $\mathrm{fe}_{3} \mathrm{O}_{4}$, SION6 and free Soy lecithin

\begin{tabular}{lccc}
\hline Bond & Naked Fe $_{3} \mathrm{O}_{4}$ & SION & Soy Lecithin \\
\hline v (Fe-O) & 571 & 580 & \\
$v(\mathrm{HO}-\mathrm{H})$ stretching & 3412 & & \\
$\cup(\mathrm{C}=\mathrm{O})$ & & 1624 & 1620 \\
$v(\mathrm{P}-\mathrm{O})$ & 1075 & 1075 \\
$v\left(\mathrm{C}-\mathrm{H}, \mathrm{CH}_{2}\right.$ and $\left.\mathrm{CH}_{3}\right)$ & & $1322-1400$ & $1331-1427$ \\
$v(\mathrm{C}-\mathrm{O}-\mathrm{C})$ & 1153 & 1160 \\
$v($ choline-containing & & 1020 & 1020 \\
phospholipids) & & \\
\hline
\end{tabular}




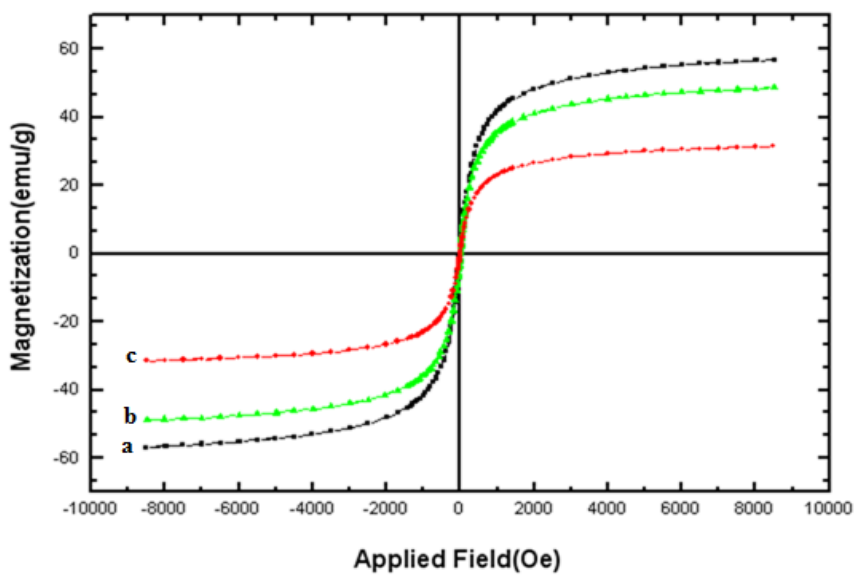

Fig. 3: Magnetic curves of: a) $\mathrm{Naked}_{3} \mathrm{O}_{4}$, b), $\mathrm{SPION}_{1.5}$ and c) $\mathrm{SPION}_{6}$
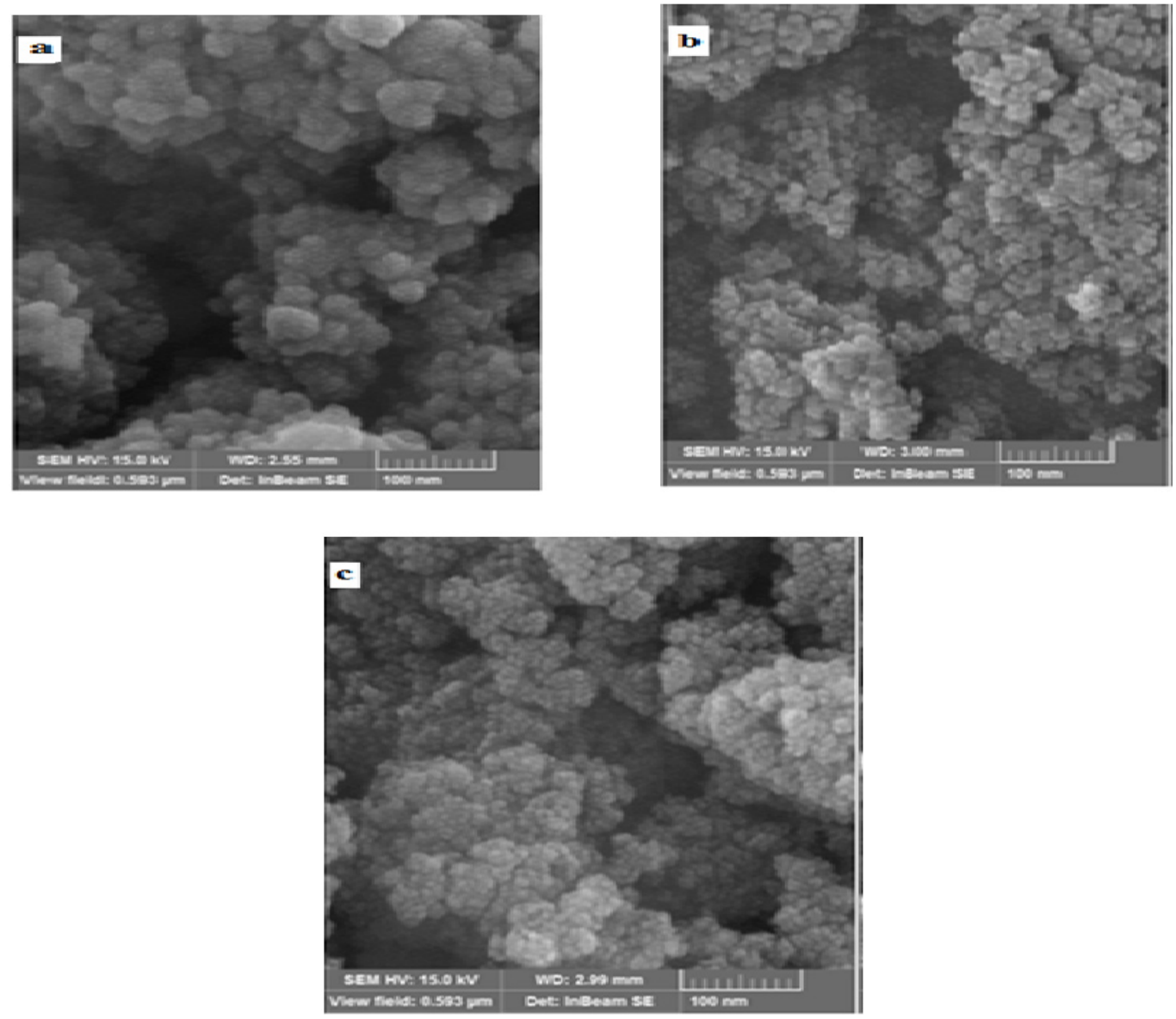

Fig. 4: SEM image of: a) Naked $\mathrm{Fe}_{3} \mathrm{O}_{4}$, b) $\operatorname{SION}_{1.5}(b)$ and c) $\operatorname{SION}_{6}$ 
coated $\mathrm{Fe}_{3} \mathrm{O}_{4}$ nanoparticles prepared by this method was decreased by increasing concentration of soy lecithin. This phenomena can be related to the nature of soy lecithin which is a mixture of phospholipids with phosphatidylcholine (PC) as a main component (up to $98 \% \mathrm{w} / \mathrm{w}$ ). Noting that, phosphatidyl cholines molecules are amphiphatic (both hydrophilic and hydrophobic), and in accordance with other authors ${ }^{13}$, we can conclude that, the SL in aqueous environment can make bilayer structure containing an aqueous phase entrapped by lipid bilayers, ${ }^{14}$ labled as vesicles and can be encapsulate a region of aqueous solution containing ferrous, ferric and hydroxide ions within a hydrophobic membrane. As a result, iron oxide nanoparticles were formed in the limited size in the liposomes vesicles.

\section{FTIR study}

Fourier transform infrared spectroscopy can be used in order to identify the soy lecithin presence on $\mathrm{Fe}_{3} \mathrm{O}_{4}$ nanoparticles surface. The FT-IR spectra of the free soy lecithin (a), soy lecithin coated iron oxide nanoparticles SPION $_{6}$ (b) and Naked (SPION) (c) are given in Fig.2. In this figure, naked iron oxide nanoparticles indicate strong band at $571 \mathrm{~cm}^{-1}$ that is assigned to the stretch vibration mode of $\mathrm{Fe}-\mathrm{O}$ bond. Similar peaks have been observed in the spectrum of the soy lecithin coated iron oxide nanoparticles (SPION) at $580 \mathrm{~cm}^{-1}$. The formation of soy lecithin coating on the surface nanoparticles was confirmed through the comparison of soy lecithin and SPION spectra (Table 1). Other additional bands observed peaks at $3710 \mathrm{~cm}^{-1}$ and $3400 \mathrm{~cm}^{-1}$, which indicated the presence of $\mathrm{N}-\mathrm{H}$ stretching and $\mathrm{O}-\mathrm{H}$ stretching of amino group and hydroxyl group as well as the bands at about 1245 attributed to the presence of $\mathrm{P}=\mathrm{O}$ (phosphomoyl) group ${ }^{15}$ and appearance of a new broad band at about $2400 \mathrm{~cm}^{-1}$ in soy lecithin coated SPION's spectrum can be clearly attributed

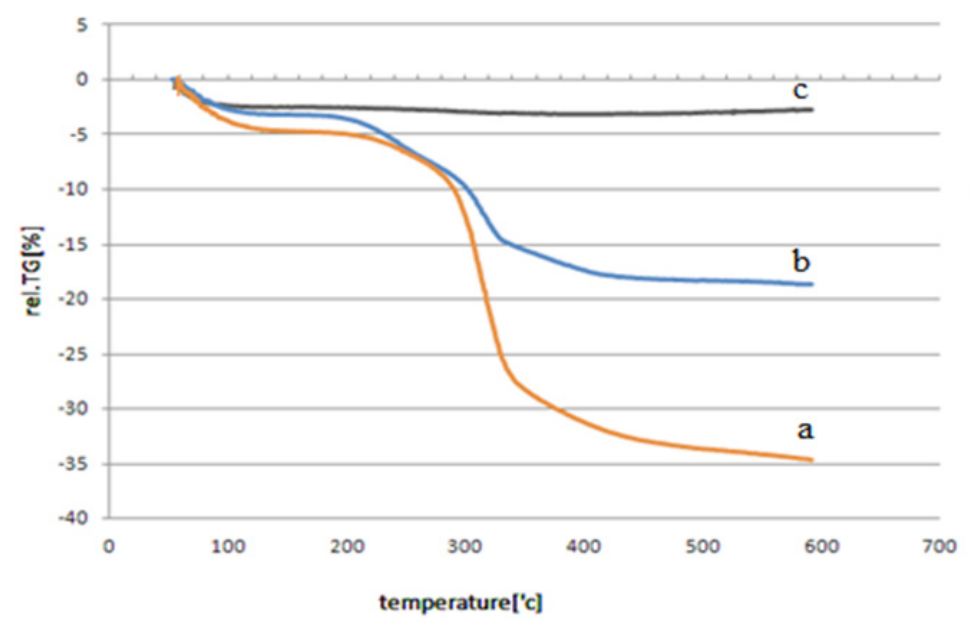

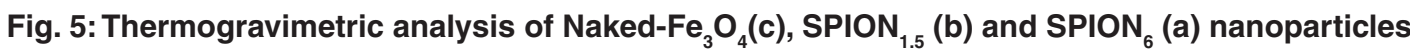

Table 2: EDX and eltra-cs analysis data for SPION $_{1.5}$ and SPION $_{6}$ nanoparticles

\begin{tabular}{ccccccc}
\hline & Element & Line & Mass[\%] & Atomic[\%] & Formula & Mass[\%] \\
\hline \multirow{2}{*}{$\operatorname{SION}_{1.5}$} & $\mathrm{Fe}$ & $\mathrm{K}$ & 66.62 & 33.89 & $\mathrm{Fe}_{3} \mathrm{O}_{4}$ & 90.68 \\
& $\mathrm{O}$ & & 25.93 & 46.75 & & \\
& $\mathrm{C}$ & & 7.82 & 18.78 & & 7.82 \\
$\operatorname{SION}_{6}$ & $\mathrm{Fe}$ & $\mathrm{K}$ & 57.81 & 25.47 & $\mathrm{Fe}_{3} \mathrm{O}_{4}$ & 79.89 \\
& $\mathrm{O}$ & & 22.53 & 34.65 & & \\
& $\mathrm{C}$ & & 19.35 & 39.64 & & 19.35 \\
\hline
\end{tabular}


to the presence of soy lecithin coats on the SPION nanoparticles.

\section{Magnetic measurements}

In order to study nanoparticles magnetic behavior and the effect of soy lecithin coating in magnetic properties, magnetization measurements for naked $\mathrm{Fe}_{3} \mathrm{O}_{4}$ and soy lecithin coated $\mathrm{Fe}_{3} \mathrm{O}_{4}$ nanoparticles ( $\mathrm{SPION}_{1.5}$ and $\mathrm{SPION}_{6}$ ) were performed. As can be observed Fig.3, all of them have a hysteresis loop with zero coercivity and remanence values. This means that these are single domains with superparamagnetic characteristics. The saturation magnetization value of naked $\mathrm{Fe}_{3} \mathrm{O}_{4}$, SPION ${ }_{1.5}$ and SPION $_{6}$ were found to be $56.8,48.5$ and 31.3 electromagnetic units per gram $(\mathrm{emu} / \mathrm{g})$ respectively. The reduction in saturation magnetization was likely due to the existence of soy lecithin on the surface of $\mathrm{Fe}_{3} \mathrm{O}_{4}$ nanoparticles. This reduction is in direct relation with the soy lecithin coating density. Nanoparticles with a denser coating, which have been synthesized in higher soy lecithin concentrations, are less sensitive to a magnetic field $^{16}$.

\section{Scanning Electron Microscopy}

The morphology of the synthesized was investigated using Scanning electron microscope. The SEM photograph of prepared samples, naked $\mathrm{Fe}_{3} \mathrm{O}_{4}, \mathrm{SPION}_{1.5}$ and $\mathrm{SNIO}_{6}$ is shown in Figure 4. SEM image shows that the morphology of the $\mathrm{Fe}_{3} \mathrm{O}_{4}$ nanoparticles is roughly spherical shape. spherical shapes are usually formed because the nucleation rate per unit area is isotopic at the interface between
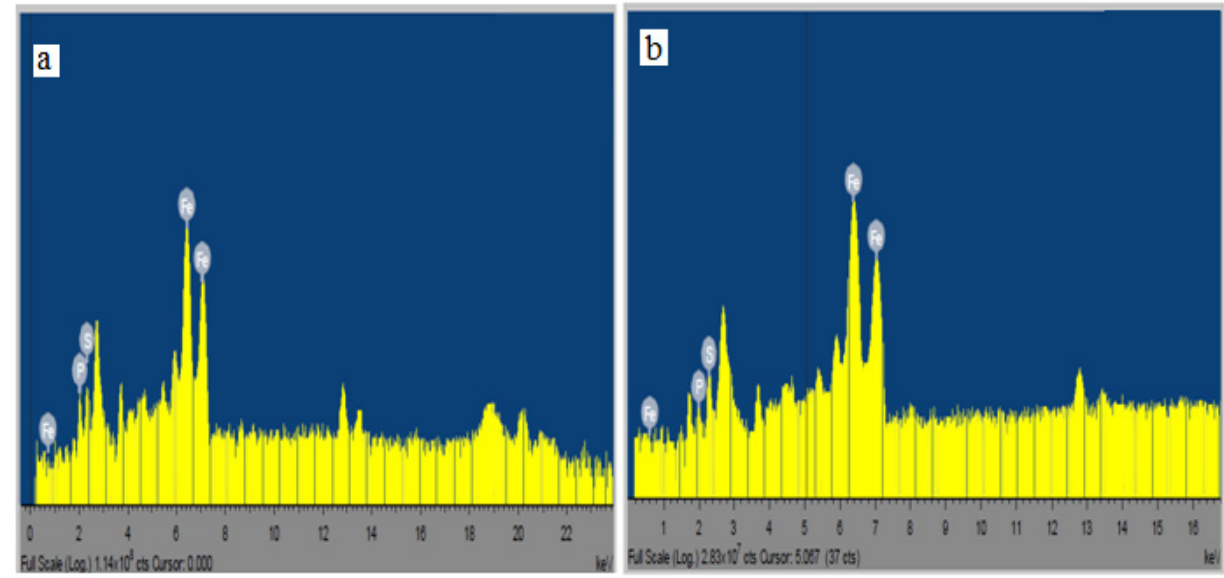

Fig. 6: EDX data curve for: a) $\operatorname{SION}_{1.5 ;}$ b) $\operatorname{SION}_{6}$
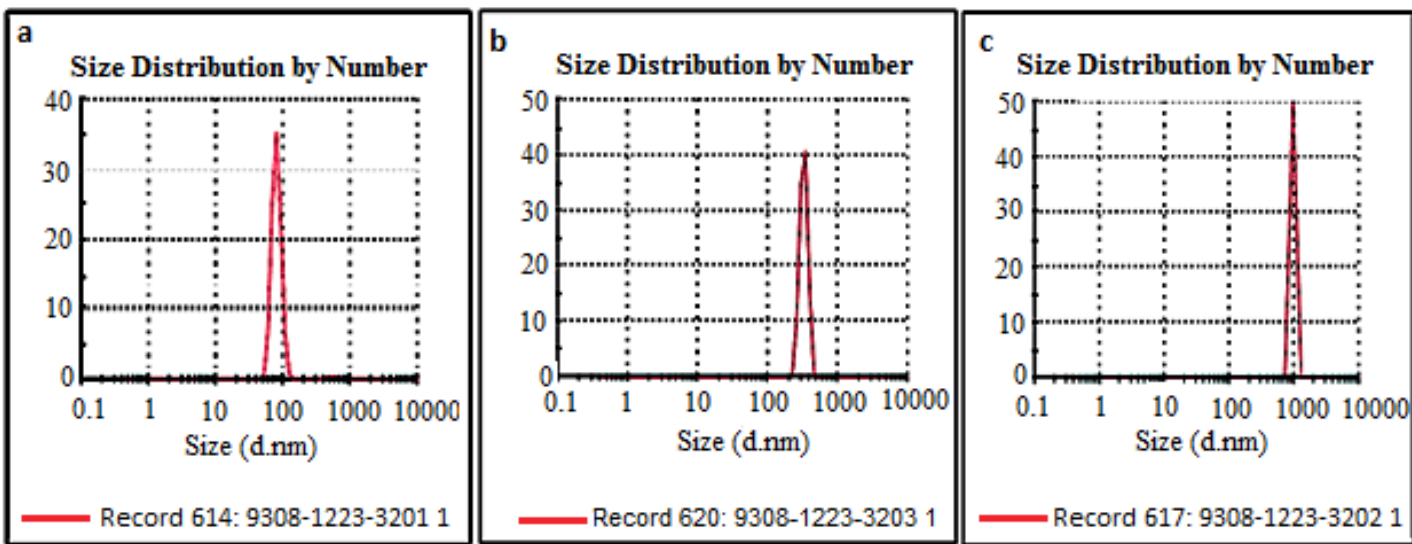

Fig. 7: Particle size distribution of: a) Naked $\mathrm{Fe}_{3} \mathrm{O}_{4}$; b) $\mathrm{SPION}_{1.5}$ and c) $\mathrm{SPION}_{6}$ 
the $\mathrm{Fe}_{3} \mathrm{O}_{4}$ magnetic nanoparticles ${ }^{17}$, which the driving force for Ostwald ripening, minimization of the surface free energy by reduction of total surface area/volume, results in the equivalent growth rate along different directions of the nucleation because the sphere has the smallest surface area per unit volume of any shape ${ }^{18}$.

\section{Thermo Gravimetric analysis}

Thermogravimetric analysis (TGA) of naked and soy lecithin coated iron oxide nanoparticles were presented in Figure 5. This analysis was carried out for powder samples $\left(7 \mathrm{mg}\right.$ ) in $\mathrm{N}_{2}$ atmosphere with a heating rate $10^{\circ} \mathrm{C} / \mathrm{min}$ from 100 up to $700^{\circ} \mathrm{C}$. For naked $\mathrm{Fe}_{3} \mathrm{O}_{4}$, no signiûcant peak appeared in the TGA curve. Also, it indicates that the weight loss in the temperature ranged from 100 to 300 only around $2 \%$. This may be justified by the loss of water remaining on surface of iron oxide nanoparticles. For soy lecithin coated iron oxide, the TGA curve shows gradual and steady weight loss in the temperature ranged from 200 to $430{ }^{\circ} \mathrm{C}$ results in the burning of soy lecithin coated. As it is shown in the figure, the further soy lecithin concentration, the greater amount of weight loss is observable.

\section{Dispersive X-ray study}

Fig. 6 and Table. 2 represent the data obtained using X-ray energy dispersion (EDX) and Eltra-cs analyzer for as prepared samples, SPION ${ }_{1.5}$ and SPION $_{6}$. These results confirm the presence of iron $(\mathrm{Fe})$, oxygen $(\mathrm{O})$ with iron abundance higher than oxygen. Eltra-cs analyzer was used to confirm the presence of soy lecithin on surface of $\mathrm{Fe}_{3} \mathrm{O}_{4}$ nanoparticles by the analysis of carbon. The results indicate that percentage of carbon in $\mathrm{SPION}_{6}$ (19.35) is more than SPION $_{1.5}$ (7.82). This results shows that, the amount of adsorbed soy lecithin on the nanoparticle surface is higher when we used higher soy lecithin concentration. This results will be confirmed by the thermo-grd avimetry analysis Spectrum.

\section{Dynamic Light Scattering (DLS) study}

The DLS measurements results of naked $\mathrm{Fe}_{3} \mathrm{O}_{4}(\mathrm{a}), \mathrm{SPION}_{1.5}$ (b) and $\mathrm{SPION}_{6}$ (c) dispersed in aqueous solution are shown in fig. 7. This figure shows that the hydrodynamic diameter for $25 \mathrm{~nm}$ particles is $78 \mathrm{~nm}$ while for 13 and $9 \mathrm{~nm}$ particles, prepared by increased soy lecithin concentration, reveal higher hydrodynamic diameter (342 and 955nm respectively). This results confirms increasing hydrodynamic diameter of the sample by increasing soy lecithin concentration.

\section{CONCLUSION}

In summary, soy lecithin coated iron oxide nanoparticles (SPION, SPION ${ }_{1.5}$, SPION $_{6}$ ) were successfully synthesized by in situ co-precipitation method. By increasing soy lecithin concentration in the preparation process, the SPION crystalline size decreased from 25 to $9 \mathrm{~nm}$. The presence of soy lecithin on the surface of iron oxide nanoparticles has been confirmed through XRD patterns and FTIR spectra respectively. The roughly spherical morphology of the soy lecithin coated SPION confirms that soy lecithin in aqueous environment has formed bilayer structures ferrous, ferric and hydroxide ions within a hydrophobic membrane. As a result, iron oxide nanoparticles were therefore formed in the limited size in the liposomes vesicles. Investigation performed by TGA and DLS analysis were finally confirmed that, SPION nanoparticles surface was protected by soy lecithin layers as a surfactant.

\section{REFERENCES}

1. Yan Wei, Bing Han, Xiaoyang Hu, Yuanhua Lin, Xinzhi Wang, Xuliang Deng Synthesis of $\mathrm{Fe}_{3} \mathrm{O}_{4}$ nanoparticles and their magnetic properties. Procedia Engineering 2012 ; 27: $632-637$.

2. Yulei Tai, Li Wang, Guangqing Yan, Jinmin Gao, Haojie Yu and Lei Zhang, Recent research progress on the preparation and application of magnetic nanospheres. Polymer International 2011; 60: 976-994.

3. J. Xie, J. Huang, X. Li, S. Sun and X. Chen., Iron oxide nanoparticle platform for biomedical applications. Curr Med Chem 2009; 16: 1278-1294.

4. Hyon Bin Na, In Chan Song, Taeghwan Hyeon. Inorganic Nanoparticles for MRI Contrast 
Agent Adv. Mater., 2009; 21:2133-2148.

5. Derong Zhu, Fuyao Liu, Lina Ma, Dianjun Liu, and Zhenxin Wang. NanoparticleBased Systems for T1-Weighted Magnetic Resonance Imaging Contrast Agents. Int $\mathrm{J}$ Mol Sci 2013 ; 14(5): 10591-10607

6. Andreas Jordan, Regina Scholz, Peter Wust, Horst FaKhling, Roland Felix Magnetic fuid hyperthermia (MFH): Cancer treatment with AC magnetic "eld induced excitation of biocompatible superparamagnetic nanoparticles. Journal of Magnetism and Magnetic Materials 1999; 201:413-419.

7. Liu-Jiang Zhou, Bo Heand Feng. Zhang. Facile One-Pot Synthesis of Iron Oxide Nanoparticles Cross-linked Magnetic Poly(vinyl alcohol) Gel Beads for Drug Delivery, ACS Appl. Mater. Interfaces, 2012; 4: 192-199.

8. Fahima Dilnawaz1, Abhalaxmi Singh1, Chandana Mohanty, Sanjeeb K. Sahoo. Dual drug loaded superparamagnetic iron oxide nanoparticles for targeted cancer therapy. Biomaterials, 2010;31:3694-3706.

9. Albert Figuerola, Riccardo Di Corato, Liberato Manna, Teresa Pellegrino. From iron oxide nanoparticles towards advanced iron-based inorganic materials designed for biomedical applications. Pharmacological Research 2010; 62: 126-143.

10. Gert Storm, Sheila 0. Belliot, Toos Daemenb, Danilo D. Lasic. Surface modification of nanoparticles to oppose uptake by the mononuclear phagocyte system. Advanced Drug Delivery Reviews 1995; 17: 31-48.

11. Sophie Laurent, Delphine Forge, Marc Port, Alain Roch, Caroline Robic, Luce
Vander Elst, andRobert N. Muller.Magnetic Iron Oxide Nanoparticles: Synthesis, Stabilization, Vectorization, Physicochemical Characterizations, and Biological Applications. Chem. Rev. 2008,;108: 2064-2110 .

12. Bragg,W.H. (1915) The structure of magnetite and the ... Nature, 1915, 95: 561

13. Theresa M. Allena, Pieter R. Cullisb. Liposomal drug delivery systems: From concept to clinical applications. Advanced Drug Delivery Reviews 2013; 65(1): 36-48.

14. Scholfield, C.R. (October 1981), "Composition of Soybean Lecithin", Journal of the American Oil Chemists' Society, 58 (10): 889-892, doi:10.1007/bf02659652, retrieved 2014.,0821 - via USDA

15. Choudhary N., Pardhi D., Bhoyar M, Isolation of soy lecithin from soy sludge, Its standardization and Behavioral study, Asian J Pharm Clin Res, 2013 ., 6, 2, , 133-136.

16. Ge Y, Zhang Y, Xia J, et al. Effect of surface charge and agglomerate degree of magnetic iron oxide nanoparticles on KB cellular uptake in vitro. Colloid Surf B Biointerfaces. 2009., 73 (2):294-301.

17. Yan Wei, Bing Han, Xiaoyang Hu, Yuanhua Lin, , Xinzhi Wang, Xuliang Deng. Synthesis of $\mathrm{Fe}_{3} \mathrm{O}_{4}$ Nanoparticles and their Magnetic Properties . Procedia Engineering, 2012.,27.,632-637.

18. Wensheng Lu, Yuhua Shen, Anjian Xie, Weiqiang Zhang.Green synthesis and characterization of superparamagnetic $\mathrm{Fe}_{3} \mathrm{O}_{4}$ nanoparticles. Journal of Magnetism and Magnetic Materials 2010., 322 .,18281833. 